\title{
Safety evaluation for bridge crane based on FTA and AHP
}

\author{
Shuai Fei ${ }^{1}$, Li Xiangdong ${ }^{1, a}$ and Fan Yali ${ }^{2}$ \\ ${ }^{1}$ Jiangsu Province Special Equipment Safety Supervision Inspection Institute, Nanjing, China \\ ${ }^{2}$ Nanjing University of Science and Technology, Nanjing, China
}

\begin{abstract}
Starting from the development status of the lifting machinery industry, this paper analyzes the data about safety accidents of bridge cranes, and identifies the assessment indicators affecting the safety performance of bridge cranes based on fault tree analysis (FTA), including fatigue factors, human factors, environmental factors, and management factors. Then, the weights of safety evaluation indicators are determined based on analytic hierarchy process (AHP). Finally, the safety evaluation system is established and demonstrated with use case diagram and role flow chart.
\end{abstract}

\section{Introduction}

There are millions of bridge cranes in China, a large number of which have exceeded the service life and the metal structures of many cranes have various crack defects 错误! 未找到引用源。. If an accident occurs, it will cause personal injury and property loss错误! 未找到引用 源。.With the development of modern science and technology, bridge cranes need not only high load capacity under complex working environment, but also to reduce the cost of raw materials for manufacturing. In a word, it is necessary to evaluate the safety performance in order to prevent crane accidents. Therefore, this paper aims to establish a safety evaluation system for bridge crane.

\section{Establishment of safety evaluation system for bridge crane}

Fatigue crack damage is one of the main failure forms of crane metal structures 错误! 未找到引用源。 In daily use, parts of hoisting machinery will cause problems such as abrasions and failures of safety protection devices 错误! 未找到引用源。

During the service period, the bridge cranes are subjected to environmental impacts. Long-term overload and other unexpected situations, and the fatigue of metal materials will weaken the function of bridge cranes. When the damage is accumulated to a certain extent, the girders will fail 错误! 未找到引用源。.Therefore, this paper combines fault tree analysis (FTA) to determine the fatigue factors that affect the safety of bridge cranes, as shown in Figure 1.

Besides the fatigue factors, human factors, environmental factors, and management factors also affect the safety performance of bridge cranes. The safety assessment indicators of bridge cranes are proposed in Table 1.

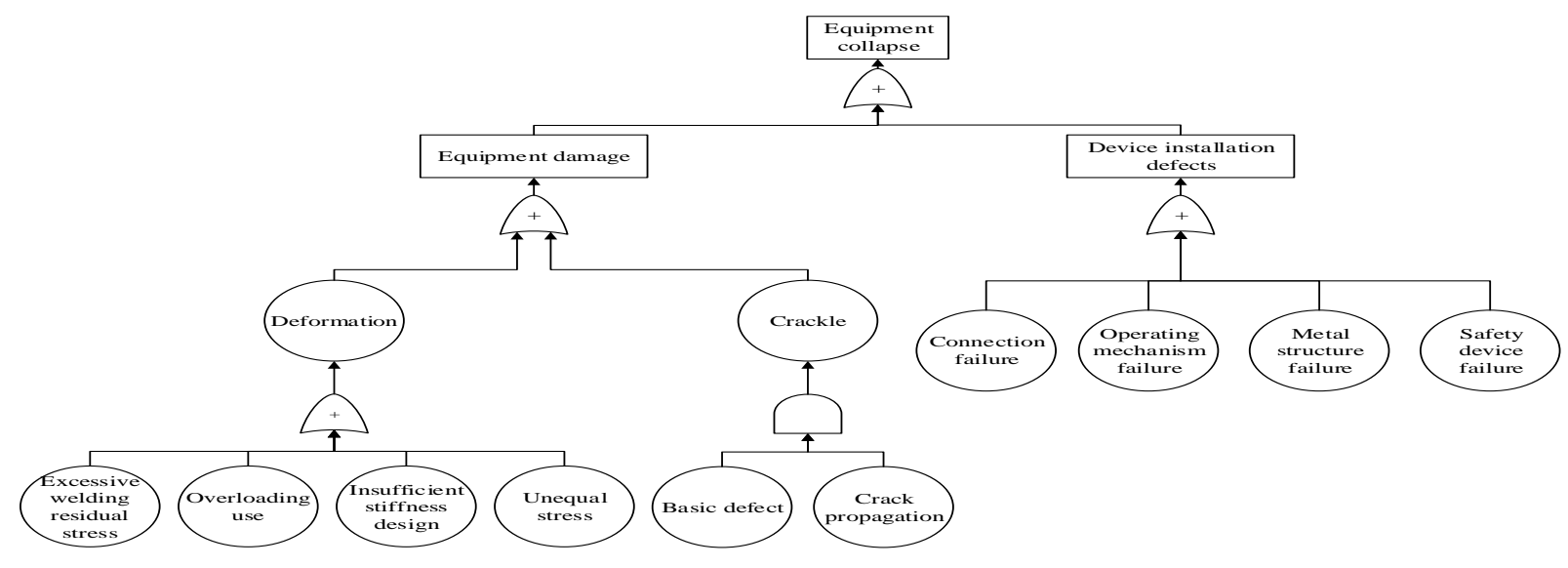

a Corresponding author: 252363775@qq.com

(C) The Authors, published by EDP Sciences. This is an open access article distributed under the terms of the Creative Commons Attribution License 4.0 (http://creativecommons.org/licenses/by/4.0/). 
Figure 1. Equipment faultanalysis diagram.

Table 1. Bridge crane safety assessment indicators.

\begin{tabular}{|c|c|c|}
\hline \multirow{10}{*}{$\begin{array}{l}\text { Fatigue factors } \\
\text { A1 }(0.522)\end{array}$} & \multirow{6}{*}{ Metal mechanisms B1(0.528) } & Surface wear degree $\mathrm{C} 1(0.31)$ \\
\hline & & Crack deformation degree $\mathrm{C} 2(0.20)$ \\
\hline & & Weld defect degree $\mathrm{C} 3(0.16)$ \\
\hline & & The fatigue life of crack $\mathrm{C} 4(0.13)$ \\
\hline & & Vibration conditions C5(0.09) \\
\hline & & Flaw detection conditions C6(0.11) \\
\hline & \multirow[t]{2}{*}{ Operating mechanisms B2(0.332) } & Retarder performances $\mathrm{C} 7(0.5)$ \\
\hline & & Brake performances $\mathrm{C} 8(0.5)$ \\
\hline & \multirow[b]{2}{*}{ Safety devices B3(0.140) } & Service life C9(0.5) \\
\hline & & Reliability C10(0.5) \\
\hline \multirow{5}{*}{$\begin{array}{c}\text { Human factors } \\
\text { A2(0.239) }\end{array}$} & \multirow[t]{3}{*}{ Operators B4(0.5) } & Mechanical workers C11(0.637) \\
\hline & & Commanders C12(0.258) \\
\hline & & Managers C13(0.105) \\
\hline & \multirow[t]{2}{*}{ Quality of personnel B5(0.5) } & Psychological quality C14(0.5) \\
\hline & & Physiological quality C15(0.5) \\
\hline \multirow{5}{*}{$\begin{array}{c}\text { Environmental factors } \\
\text { A3(0.153) }\end{array}$} & \multirow[t]{2}{*}{ Weather B6(0.341) } & Visibility C16(0.5) \\
\hline & & Wind load C17(0.5) \\
\hline & \multirow[t]{3}{*}{ Foundation B7(0.659) } & Ground deformation C18(0.582) \\
\hline & & Flatness of the ground C19(0.109) \\
\hline & & Safe distance C20(0.309) \\
\hline \multirow{4}{*}{$\begin{array}{c}\text { Management factors } \\
\mathrm{A} 4(0.086)\end{array}$} & \multirow[t]{2}{*}{ Maintenance situation B8(0.5) } & Maintenance cycle C21(0.5) \\
\hline & & Maintenance records C22(0.5) \\
\hline & \multirow[t]{2}{*}{ Inspection B9(0.5) } & Inspection cycle $\mathrm{C} 23(0.5)$ \\
\hline & & Inspection records C24(0.5) \\
\hline
\end{tabular}

\section{Determination of the weights for safety assessment indicators}

The weight of each factor is obtained by using AHP. The procedure is as follows: (1) Model a hierarchy decision model; (2) Establish a judgment matrix; (3) Synthesize these judgments to yield a set of overall priorities for the hierarchy; (4) Check the consistency; (5) Draw a final

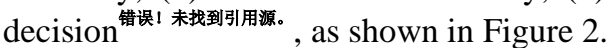

Set up the hierarchy structure of safety evaluation index system. The hierarchy architecture is divided into three levels: the target layer, the rule layer, and the scheme layer as shown in Figure 3.

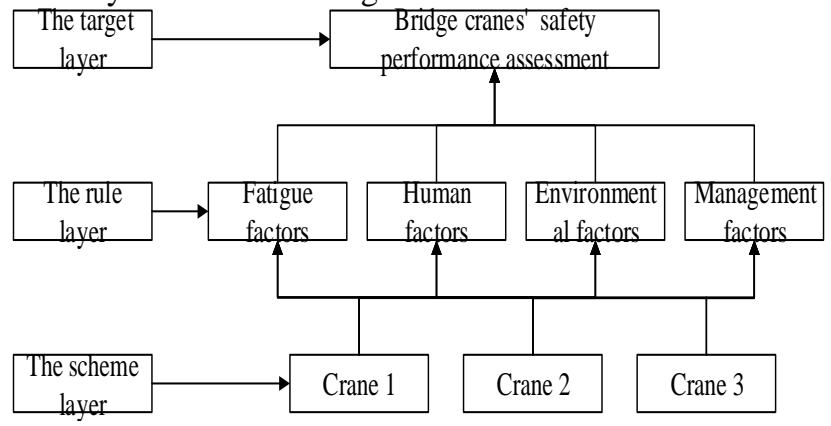

Figure 3. Hierarchy structure of bridge crane fatigue evaluation index system.

Establish a judgment matrix. First, this paper uses AHP to build a judgment matrix for peer indicators. Suppose there are $\mathrm{n}$ indicators, $\{\mathrm{A} 1$,
$\mathrm{A} 2, \ldots, \mathrm{Ai}, \ldots, \mathrm{Aj}, \ldots, \mathrm{An}\}, a_{i j}$ indicates the ratio of the importance of the index Ai to the index $\mathrm{Aj}$, that is, the element in judgement matrix A. ${ }^{a_{i j}}$ takes $1,3,5,7,9$ five scales: 1 means that the index $\mathrm{Ai}$ is as important as the index $\mathrm{Aj}$, the importance of index $\mathrm{Ai}$ is increasing than that of index $\mathrm{Aj}$ with the increase of the numbers.

Synthesize these judgments to yield a set of overall priorities for the hierarchy. After the completion of the judgement matrix, the second-level indexes are sorted and the root weight method is applied to normalize the index to get the initial weights of the indexes. This step includes calculating single-level weights and multi-level weights. This paper chooses the root weight method to calculate the maximum eigenvector of the judgment matrix. The process is as follows.

(1) Calculate the product of each row element of the judgment matrix A, the formula is as follows.

$$
m_{i}=\prod_{j=1}^{n} a_{i}
$$

(2) Calculate the $n$ roots of each row element of the judgment matrix separately, and the initial weights of the indexes at all levels are obtained after normalization, the formulas are as follow 错误! 未找到引用源。

$$
\overline{W_{i}}=\sqrt[n]{\left|m_{i}\right|}
$$




$$
W_{i}=\overline{W_{i}} / \sum_{j=1}^{n} \overline{W_{j}}
$$

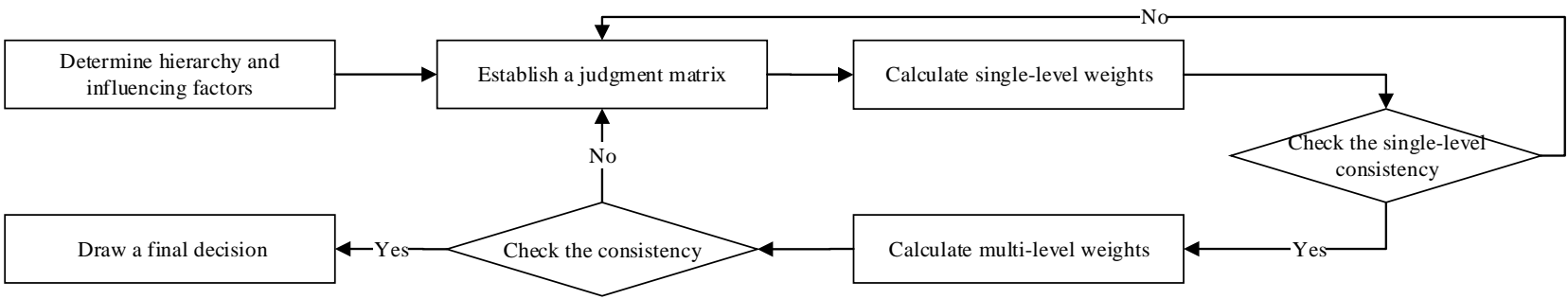

Figure 2. AHP's flow chart.

Check the consistency. It is necessary to test the random consistency of the index to ensure the logic accuracy when the initial weights are obtained. The process is as follows.

(1) Calculate the maximum eigenvalue based on the constructed judgement matrix $\mathrm{A}$, the formula is as follows.

$$
\lambda \max =\sum_{i=1}^{n} \frac{(A W)}{n W}
$$

(2) Calculate the consistency ratio $C_{R}$ according to the maximum characteristic root, and test the random consistency of the indexes at all levels, the formulas are as follow.

$$
\begin{aligned}
& C=\frac{\lambda_{\max }-n}{n-1} \\
& R=\frac{\bar{\lambda}_{\max }-n}{n-1}
\end{aligned}
$$

(3) Calculate the proportion of random consistency, the formula is as follows.

$$
C_{R}=\frac{C}{R}
$$

When the consistency ratio of the random consistency test satisfies the index, the original judgment matrix is maintained, and the initial weights are the final weights, otherwise, the original judgment matrix is adjusted and the initial weights are recalculated until the index is satisfied.

Results. Here is a demonstration of the pairwise comparison and priority calculation, as shown in Table 2 (Take metal mechanism, operation mechanism and safety device as an example).

The influencing factors and weights of the safety assessment indicators are shown in Table 2.

\section{Design of safety evaluation system for bridge crane}

Software function requirements and performance requirements are determined based on the above analyses. The functional modules of the bridge crane safety evaluation system are divided into five modules: information acquisition module, information storage module, information query module, parameter change module and system management module. Each module has a specific functional division and different functional requirements for different user identities.

According to the established model, the users and administrators' permissions are different, and the corresponding application processes are also different. Administrators can log in directly without registration, and can modify indicator parameters. The users enter the main interface by logging in or registration, and can view, modify, add, delete the stored bridge crane information, and so on. The specific process is shown in Figure 4.

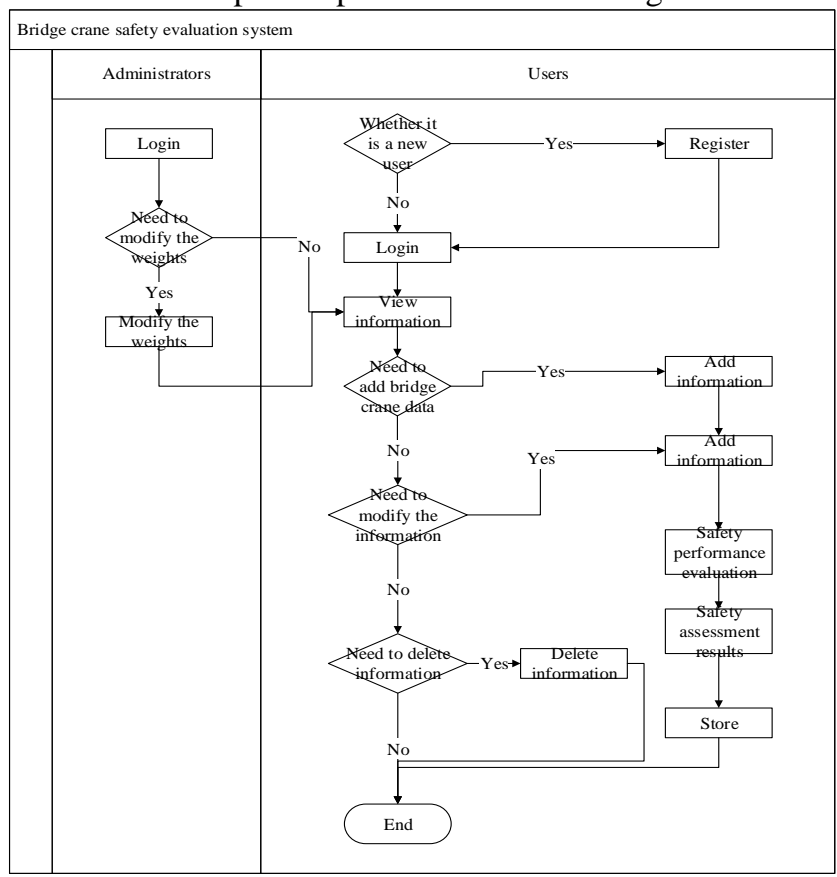

Figure 4. System flow chart.

Table 2. A case of the pairwise comparison and priority calculation $(\mathrm{CR}=0.046)$.

\begin{tabular}{|l|l|l|l|c|l|}
\hline & $\begin{array}{l}\text { Metal } \\
\text { mechanisms }\end{array}$ & $\begin{array}{l}\text { Operation } \\
\text { mechanism }\end{array}$ & $\begin{array}{l}\text { safety } \\
\text { device }\end{array}$ & $\begin{array}{l}\text { Geometric means } \\
\text { priorities }\end{array}$ \\
\hline Metal mechanisms & 1 & 2 & 3 & $\sqrt[3]{1 \times 2 \times 3}=1.817$ & 0.528 \\
\hline
\end{tabular}




\begin{tabular}{|l|l|l|l|l|l|}
\hline operation mechanism & $1 / 2$ & 1 & 3 & 1.145 & 0.332 \\
\hline safety device & $1 / 3$ & $1 / 3$ & 1 & 0.481 & 0.140 \\
\hline
\end{tabular}

\section{Summary}

This paper presents a safety performance assessment model for bridge cranes and uses the analytic hierarchy process (AHP) to determine the weights of the indicators in the model. At the same time, this article uses information software to achieve the safety assessment of bridge cranes. The software can make the assessment of bridge cranes more convenient and faster, and provides a basis for the management and maintenance of bridge cranes.

\section{Acknowledgment}

This work was financially supported by the Program of Science Foundation of General Administration of Quality Supervision and Inspection of Jiangsu Province (KJ175940). The supports are gratefully acknowledged.

\section{References}

1. Zhan Weigang, Fatigue life prediction based on crack propagation and its Application in crane metal structures, Harbin Institute of Technology (2014).

2. Xia Lu, Analysis and Preventive Measures of Common Mechanical Accidents of Cranes, Brand and standardization. 10 (2015) 83-84.

3. Li Yidong, Safety Evaluation of Metal Structure of Shipbuilding Crane Based on Fatigue Failure, Zhejiang University (2012).

4. Chen Aiqing, Statistics on safety risks and defects of cranes, China Chemical Trade. 7 (2015) 110.

5. He Yali, Study on fatigue life analysis and safety evaluation method of bridge crane, Beijing University of Chemical Technology (2014).

6. Wei C C, Chien C F, Wang M J J. An AHP-based approach to ERP system selection, J. International Journal of Production Economics, 2005, 96(1):47-62.

7. Ramanathan R, Ganesh L S. Group preference aggregation methods employed in AHP: An evaluation and an intrinsic process for deriving members' weightages, J. European Journal of Operational Research, 1994, 79(2):249-265. 